\title{
Os fundamentos da relação teoria e prática no estágio em Serviço Social
}

\author{
Moíza Siberia Silva de Medeiros \\ Instituto Federal de Educação, Ciência e Tecnologia do Ceará \\ (IFCE)
}

Os fundamentos da relação teoria e prática no estágio em Serviço Social

Resumo: Este artigo discute os aspectos teórico-metodológicos da relação entre teoria e prática na formação profissional e no processo de estágio em Serviço Social, destacando duas concepções antagônicas: a pragmática e a marxiana. É fruto de reflexões teóricas e das experiências acumuladas no processo de supervisão acadêmica de estágio em Serviço Social. Apresenta os desafios enfrentados no processo de supervisão de estágio na contemporaneidade.

Palavras-chave: Fundamentos teórico-metodológicos. Teoria e Prática. Formação Profissional. Supervisão de Estágio em Serviço Social.

\section{The Fundaments of the Relation between Theory and Practice in Social Work Internships}

Abstract: This article discusses theoretical-methodological aspects of the relationship between theory and practice in professional education and in internships in social work, highlighting two antagonistic perspectives: the pragmatic and the Marxian. It is the fruit of theoretical reflections and experiences accumulated in academic supervision of social work internships. It presents challenges faced in the contemporary supervision process.

Keywords: Theoretical-methodological fundaments. Theory and Practice. Professional Education. Supervision of Internships in Social Work. 


\section{Introdução}

É recorrente ouvirmos de alguns alunos de Serviço Social que o ingresso no estágio é um momento privilegiado da formação profissional porque é nele que "aprenderão o que o assistente social faz", pois entrarão em contato com a prática. Na ânsia de descobrir "para que serve o Serviço Social na prática" ou de "aplicar os conhecimentos que adquiriram em sala de aula", muitos alunos acabam se antecipando e ingressam no estágio antes mesmo do período obrigatório previsto nas diretrizes curriculares do curso de Serviço Social. Também tem sido comum ouvir de alguns profissionais que o curso de Serviço Social é demasiadamente teórico, não disponibilizando os conhecimentos práticos para a intervenção profissional, ocasionando no discurso de que "na prática a teoria é outra". A recorrência em privilegiar a prática como momento do "aprender fazendo" é próprio da razão instrumental ${ }^{1}$ burguesa que incorporou ao saber a ideia de utilidade, daí decorre o equívoco de buscar dar uma "aplicabilidade prática" às teorias e conceitos "aprendidos" em sala de aula, pois se só é útil o que aplicável, e o que pode gerar resultados, numa profissão eminentemente interventiva como é o Serviço Social, que apresenta a necessidade de criar metodologias através da exigência efetiva de que as ações profissionais gerem um resultado objetivo, tal ideia se ancora com bastante facilidade se não se fizer uma leitura crítica da realidade e dos fundamentos da profissão. Esta perspectiva está ancorada na recusa de pensar a realidade a partir de uma matriz ontológica materialista fundada na práxis, ocasionando numa compreensão equivocada do que é teoria e da relação teoria e prática, que fragiliza o entendimento acerca das requisições e competências profissionais na ordem burguesa, possibilitando que o pragmatismo, o instrumentalismo e o metodologismo se coloquem como solução para o suposto descompasso entre teoria e prática, não obstante a profissão venha buscando desde 1980, através do seu amadurecimento teórico, via aproximação com a tradição marxista, superar tais perspectivas Guerra (2000).

Corroborando com Guerra (2000; 2011; 2013), Santos (2012) e Forti e Guerra (2013) - que muito contribuem para o adensamento do debate acerca da relação teoria e prática na profissão, construindo saberes acerca da dimensão técnico-operativa da profissão como forma de ser e aparecer, e de construir sua imagem social -, discutiremos neste artigo a relação teoria e prática na formação profissional em Serviço Social a partir de dois marcos: a concepção de teoria e prática na sociedade burguesa, os elementos teórico-metodológicos desta e sua influência na formação profissional em Serviço Social e no processo de supervisão de estágio; o legado da teoria marxiana para a compreensão da unidade dialética entre teoria e prática e suas contribuições para um processo de formação profissional e de supervisão de estágio crítico, reflexivo e propositivo ${ }^{2}$.

O artigo está dividido em três secções: na primeira discutimos acerca da influência do pragmatismo na profissão e de que forma fragilizou a relação teoria e prática no estágio e na (acréscimo) formação profissional em Serviço Social; na segunda, apresentamos os avanços da profissão no que se refere à supervisão de estágio a partir de uma formação profissional alicerçada na unidade dialética teoria e prática; por último, trazemos algumas reflexões acerca dos desafios enfrentados no processo de supervisão de estágio na contemporaneidade, a fim de garantir que a formação profissional não instrumentalize seu fazer, mas antes se fundamente na instrumentalidade da profissão enquanto mediação fundamental do exercício profissional.

\section{Fundamentos teórico-metodológicos da relação teoria e prática e suas inflexões na formação profissional e no estágio em Serviço Social}

\subsection{Pragmatismo na formação profissional e no estágio em Serviço Social}

Fala-se muito em prática do Serviço Social para se referir às atividades realizadas pelo assistente social nas instituições, confundindo prática com prática profissional, esta última entendida, muitas vezes, numa perspectiva pragmática e tarefeira. $\mathrm{O}$ fato de o Serviço Social ser uma profissão de natureza interventiva, requisitada a dar respostas às expressões da questão social, imprime nos profissionais, rotinizados pelo cotidiano institucional, um dever de resolutividade dos casos, que ganha materialidade nos encaminhamentos automatizados. Em um cenário onde a exploração do trabalho torna o assistente social cada vez mais assoberbado de obrigações e de tarefas, num contexto no qual a demanda vem se avolumando devido à ampliação das políticas sociais (a ampliação dos postos de trabalho não seguiu no mesmo ritmo, nem em quantidade suficiente para atender à demanda), a automatização dos encaminhamentos é a forma que o profissional encontra para tentar, minimamente, atender a população a fim de não a deixar sem resposta. É aí que se reproduz o discurso tão pronunciado entre alguns profissionais e também estudantes de Serviço Social: de que o curso de Serviço Social tem muita teoria, mas que não tem aplicabilidade nenhuma no cotidiano institucional. Queixam-se de o curso não ensinar o como fazer, principalmente a utilizar os instrumentos e técnicas com as quais se deparam 
na instituição. Criticam a teoria marxista por não ter uma aplicabilidade prática. Cria-se uma cisão entre teoria e prática, e entre os que pensam e os que executam. Tal divisão cria duas vertentes de conhecimento: de um lado o teoricismo e de outro praticismo, criando graus de hierarquia entre teoria e prática. Na primeira interpretação, valoriza-se o saber teórico como único possível de lançar luz sobre a realidade, a segunda, por sua vez, defende que o conhecimento emana da prática e a teoria seria uma sistematização deste.

O pragmatismo deita raízes no irracionalismo e no positivismo, este, por sua vez, influenciou a profissão de Serviço Social mais profundamente durante o processo de renovação da profissãa ${ }^{3}$, na direção denominada por Netto (2010) de modernização conservadora ${ }^{4}$ que buscava dar à profissão um corpus técnico-operativo integrador, dinamizador e interveniente da proposta desenvolvimentista. Yazbek $(2009$, p. 6) assim analisa a influência do positivismo na profissão:

No caso do Serviço Social, um primeiro suporte teórico metodológico necessário à qualificação técnica de sua prática e à sua modernização vai ser buscado na matriz positivista e em sua apreensão manipuladora, instrumental e imediata do ser social. [...]. É a perspectiva positivista que restringe a visão de teoria ao âmbito do verificável, da experimentação e da fragmentação. [...]. Particularmente em sua orientação funcionalista, esta perspectiva é absorvida pelo Serviço Social, configurando para a profissão propostas de trabalho ajustadoras e um perfil manipulatório, voltado para o aperfeiçoamento dos instrumentos e técnicas para a intervenção, com as metodologias de ação.

O pragmatismo, como vertente do pensamento, fertiliza o projeto capitalista quando advoga que uma concepção é verdadeira se for útil, sendo que a utilidade está na capacidade de resolutividade e de êxito na aplicabilidade (HAACK, 2002). Neste sentido, para os pragmáticos, uma teoria só é válida se tiver uma aplicabilidade prática. Porém, como teoria e prática possuem naturezas diferentes, passar de uma para a outra sem as devidas mediações ocasionará de um lado uma teoria que mais parece uma caricatura do real, de outro uma intervenção imediatista, fragmentada e reiterativa (GUERRA, 2013).

A influência do positivismo e do pragmatismo na formação profissional em Serviço Social no período que vai dos anos 1930 até 1950 esteve eminentemente marcada pela perspectiva do treinamento de pessoal para dar respostas às demandas provenientes das desigualdades originárias do sistema capitalista em emergência, copiando o modelo americano, que tinha um claro viés desenvolvimentista. Neste período a racionalidade técnica busca superar a racionalidade assistencial, daí o discurso da modernização da profissão implicar na valorização do uso de instrumentos e técnicas e a formação profissional estar direcionada à aprendizagem destas. Cabe ressaltar que é apenas nos anos de 1950 que a formação profissional em Serviço Social é regulamentada em Nível Superior através da Lei n. 1.899, de 13/06/1953, regulamentada, pelo decreto-lei n. 35.311, de 08/04/1954. De acordo com a referida Lei, o primeiro ano do curso deveria destinar-se à parte teórica, o segundo ter de maneira equilibrada a teoria e a prática e no terceiro ano deveria haver preponderância da parte prática. Prevalecia, pois a cisão entre teoria e prática, e a ideia de que primeiro se aprende a teoria para depois aplica-la na prática. Não havia disciplina específica de estágio, sendo que o estágio era denominado de prática, que consistia na aprendizagem do "como fazer", realizado por meio de visitas a obras sociais e às famílias necessitadas (RIBEIRO, 2013).

A cisão entre teoria e prática presente no processo de modernização conservadora e a ênfase dada à dimensão interventiva da profissão provocou o empobrecimento da profissão e gerou, a partir da interconexão da razão instrumental e da racionalidade formal-abstrata ${ }^{5}$, o que Guerra (2000) chamou de metodologismo e instrumentalismo. Estas tendências se apresentam de três formas intrinsecamente imbricadas: a defesa do Serviço Social enquanto técnica social: buscava dotar o Serviço Social de cientificidade e conferir um ar de modernidade à profissão a partir da adoção de modelos de intervenção profissional, valorizando os procedimentos técnico-instrumentais ${ }^{6}$; a maneira de conceber o instrumental técnico do Serviço Social: considerandoo como conjunto de instrumentos e técnicas neutros que devem ser direcionados pela visão de mundo do assistente social de acordo com suas finalidades, ao mesmo tempo em que os instrumentos direcionam o agir profissional, ocasionando a deificação do instrumental técnico; o entendimento de competência profissional: diretamente ligada à capacidade do assistente social utilizar-se do arsenal técnico e aplicar os modelos de intervenção (GUERRA, 2000).

Partindo desta concepção de teoria e prática, na qual o instrumental técnico ganha vida e subsume à vontade dos sujeitos, a formação profissional neste período estava voltada para o "ensinar a fazer", perspectiva que foi potencializada com a demanda aumentada por assistentes sociais com a criação das instituições sociais por parte do Estado na década de 1940, que exigia profissionais tecnicamente qualificados para operarem as técnicas de Serviço Social de Caso e de Grupo, tendo por objetivo a eficácia e eficiência da ação profissional. Segundo Lewgoy (2010), dos anos de 1950 a 1960 a formação profissional em Serviço Social se aproximou do 
pensamento educativo vigente que recebia influência do escolanovismo ${ }^{7}$, enfatizando a ideia de que o aluno aprende melhor aquilo que ele mesmo faz, ou seja, valoriza-se o "aprender fazendo". Percebe-se neste período a ênfase da formação profissional cada vez mais voltada para a racionalidade técnica da profissão, com o enfoque no aprendizado das técnicas e metodologias de ação. De acordo com Guerra e Braga (2009) e Netto (2010), o aprofundamento da ditadura exigiu da profissão o deslocamento dos traços tradicionais para a adoção de procedimentos racionais, incorporando à profissão ações administrativas, de controle e verificação, segundo critérios burocráticos-administrativos. Guerra e Braga (2009, p. 7) apontam que:

"Nesse contexto, a formação profissional também havia de ser reformulada: empreende-se a uma articulação entre as preocupações operativas e os recentes conteúdos teóricos apropriados das disciplinas das ciências sociais, em especial, da psicologia, sociologia, administração (com destaque para os conhecimentos da administração científica do trabalho), dotando o profissional de um perfil fundamentalmente tecnocrático".

Percebe-se, portanto, que até os anos de 1960, a formação profissional em Serviço Social estava imbuída de formar profissionais cujo perfil profissional requisitado era funcional aos interesses do capital, reproduzindo tanto a visão de mundo burguesa, quanto contribuindo para a perpetuação do capitalismo. Cabe ressaltar que a ênfase dada no aspecto técnico-operacional da profissão, na competência técnica dos profissionais e na elaboração de uma metodologia do e para o Serviço Social estava diretamente vinculada ao contexto histórico da época que limitava o questionamento da profissão quanto à sua direção social. A crítica que a profissão fez, pois, foi uma autocrítica voltada para o seu fazer, quanto à sua metodologia, daí a modernização da profissão não ter possibilitado a ruptura com o conservadorismo. O estágio neste período não apresentava uma ampla conexão com a teoria, esta vista como apêndice deste processo e restrita ao âmbito da academia. Os Trabalhos de Conclusão de Curso (TCC), realizados naquela época, tinham a característica de se configurarem como relatos das experiências de estágio, muitas vezes limitando-se a meras descrições do que havia sido realizado e do que ocorreu de mudanças na realidade, sem se preocupar em analisar as múltiplas determinações desta. Neste sentido, tais produções revelam que o estágio era compreendido apenas como lugar do fazer prático, e a reflexão teórica limitada à concepção de sistematização da prática a partir da descrição etapista, superficial e procedimental das ações profissionais. Percebe-se, pois, que o processo de estágio cindia teoria e prática, obscurecendo as contradições da realidade e depositando e apostando na potencialidade dos indivíduos e na competência técnica do profissional para a superação das mazelas sociais.

\subsection{Perspectiva marxista e suas contribuições à formação profissional e ao estágio em Serviço Social}

A discussão acerca da relação teoria e prática como unidade dialética é relativamente recente no âmbito da profissão de Serviço Social, diz respeito à aproximação da profissão às fontes genuínas da teoria de Marx iniciada na década de 1980 e mais largamente difundida nos anos de 1990 em diante. A gênese, no entanto, da aproximação da profissão com a teoria marxista, ainda que de forma enviesada, se dá ainda no final dos anos de 1960, início dos anos de 1970, com significativas repercussões no seio profissional, como veremos a seguir. Nas décadas de 1960/70, diante das efervescências político-culturais da época, parcelas de assistentes sociais reivindicavam novos padrões teóricos e culturais, critica-se a funcionalidade da profissão ao capital e a perspectiva metodológica adotada a partir da proposta modernizadora que potencializou o tradicionalismo e o conservadorismo. Chega-se, pois, à direção de intenção de ruptura do processo de renovação da profissão da qual é marco o Método BH elaborado em meados dos anos de 1970. Santos (2007, p. 166) aponta a proposta do referido método:

Nossa proposta na Escola era romper com o esquema 'tradicional' do Serviço Social, mudar os elementos teóricos da formação profissional, enriquecê-los com as Ciências Sociais e dar muita ênfase na busca de novos campos de trabalho e práticas profissionais que ampliassem os horizontes ate então demarcados pela visão e prática tradicionais e assistencialistas da profissão.

O Método BH é fruto da aproximação de setores do Serviço Social à teoria marxista, se colocando como contraponto tanto das ideias positivistas que vinham acompanhando a profissão desde seu processo de institucionalização, quanto as de cariz fenomenológico que começam a influenciar parcelas de profissionais na década de 1970. Embora, conforme aponta Netto (2010) e Ortiz (2010), a intenção de ruptura em sua emersão inicial, a partir do Método BH, tenha permanecido por longos anos isolada, na primeira metade dos anos de 1980, é esta perspectiva que irá polemizar acerca da direção política do Serviço Social e possibilitar a constru- 
ção de uma imagem renovada da profissão anos depois (ORTIZ, 2010). Cabe aqui apontar que as contribuições do "Método BH" para se pensar hoje a relação teoria e prática na profissão está mais relacionada à sua proposição global de alternativa ao tradicionalismo e à formulação de um projeto profissional, tendo em vista que a aproximação enviesada que fez ao marxismo possibilitou conceber a relação teoria e prática de modo empirista, formalista e (neo)positivista (NETTO, 2010).

A crítica que se faz ao Método $\mathrm{BH}$ no que diz respeito à relação entre teoria e prática que se repercute na forma de compreender método, teoria e ciência, está em não ter rompido com o metodologismo que já acompanhava a profissão, devido a três fatores apontados por Netto (2010): a teoria é reduzida ao conhecimento científico do mundo, a atividade teórica é reduzida a procedimentos sistematizadores, e o método profissional é entendido como uma especialidade do método científico a partir do qual se interpreta e transforma a realidade. Embora tais críticas sejam pertinentes e necessárias, não se pode negar que o Método BH, para além das contribuições já destacadas, trouxe propostas significativas para repensar a formação profissional em Serviço Social cujo eixo central da proposta estava na "formação de um agente profissional em que as capacidades técnicas estariam criticamente consteladas por uma sensibilidade política, respaldada por informação teórica e disposição investigativa" (NETTO, 2010, p. 289).

Além da formulação do Método BH, ainda na década de 1980, no marco da intenção de ruptura, outros acontecimentos levaram a profissão a repensar a formação e o exercício profissional, entre os quais: III CBAS, o Congresso da Virada (1979) e a aprovação do Currículo Mínimo para os Cursos de Serviço Social, reconhecido pelo MEC em 1982, fruto da XXI Convenção da ABESS em Natal, RN (1979). O Currículo Mínimo de 1982 tinha por objetivo superar a fragmentação do tripé caso, grupo e comunidade, introduzindo no Currículo as disciplinas de Teoria, Metodologia e História do Serviço Social, embora o eixo da área profissional tenha ficado centrado na Teoria e na Metodologia, o novo currículo dicotomizou teoria e prática a partir da separação destas em disciplinas diferentes, além de considerá-las de forma desistoricizada uma vez que a disciplina de História também era autônoma. Sua concepção de estágio também dicotomizava teoria e prática, uma vez que "o estágio curricular cuida da aprendizagem prática que se dedica ao desenvolvimento de habilidades técnicas [...], já a aprendizagem teórica é desenvolvida apenas nas disciplinas ditas teóricas, pois elas também não tratam da prática" (RIBEIRO, 2013, p. 93). Neste sentido, a formação profissional em Serviço Social continuou a realimentar a ideia de que a teoria deve ser convertida em modelos para a intervenção, separando pensamento e ação em momentos distintos da formação profissional, daí o surgimento da ideia de que o estágio era o espaço do ensino e do aprendizado prático.

No contexto da década de 1990, diante das exigências postas à profissão a partir do novo perfil profissional requisitado e balizado pelos princípios ético-profissionais posto pelo Código de Érica de 1993, e pelas competências e atribuições regulamentadas pela Lei n. 8662/93, a revisão curricular torna-se necessária e se concretiza a partir da aprovação das Diretrizes Curriculares pela ABEPSS em 1996. De acordo com Ortiz (2013, p. 3):

as Diretrizes Curriculares aprovadas pela ABEPSS em 1996 sustentam-se nos aportes da Teoria Social Crítica (esta apoiada no pensamento marxiano) e indicam que a formação profissional deve considerar o Serviço Social como uma totalidade, e neste sentido, determinado historicamente e atravessado por múltiplas determinações de natureza econômica, política, cultural e ideológica. Tal concepção exige a constituição de um profissional com clara perspectiva crítica, ciente do processo histórico brasileiro e suas relações com o capitalismo mundial, das particularidades assumidas pelas classes sociais no Brasil e pelo Estado, que sem eliminar os traços arcaicos, modernizou-se no trato das expressões da 'questão social', combinando repressão com políticas sociais.

Sabe-se, porém, que durante os anos 2000 o Ministério da Educação a partir das reformas no Ensino Superior, fez modificações nas propostas postas nas Diretrizes Curriculares da ABEPSS de 1996, flexibilizando tal proposta curricular, que acabou por repercutir diretamente na concepção de teoria e prática que deve estar presente na formação profissional. A categoria, no entanto, tem se posicionado no intuito de garantir em seus espaços de formação a articulação da Unidade Teoria-Prática, como se pode perceber na formulação dos documentos que a categoria vem produzindo nos últimos anos, como é o caso da Política Nacional de Estágio da ABEPSS de 2009, e a Resolução n. 533 do CFESS, instrumentos importantes que integram o Projeto de Formação Profissional do Serviço Social na atualidade. Isso não acontece sem limites e contradições, diante das realidades institucionais, questões que não daremos conta de discutir aqui. Cabe ressaltar que a concepção de formação profissional que se fortalece na categoria a partir dos anos 1990, também irá repercutir na concepção de estágio como espaço de articulação entre teoria e prática, conforme está preconizado na PNE: “O estágio supervisionado curricular [...] Caracteriza-se pela atividade teórico-prática, efetivada por meio da 
inserção do(a) estudante nos espaços sócio-institucionais nos quais trabalham os(as) assistentes sociais, capacitando-o(a) nas dimensões teórico-metodológica, ético-política e técnico-operativa para o exercício profissional" (ABEPSS, 2010, p. 14).

Cabe indicar, por conseguinte, o que se está chamando por Unidade Teoria-Prática tão cara à profissão se se quer que a intervenção profissional rompa com posturas pragmáticas e conservadoras. Partindo do pressuposto que a possibilidade de questionar a ordem burguesa só é possível mediante a leitura crítica da realidade, esta pressupõe a articulação teoria e prática enquanto unidade no diverso. Na perspectiva históricocrítica, a teoria e a prática se colocam como unidade dialética tendo em vista que "a afirmação de que a teoria é um modo de ler e interpretar a realidade implica afirmar que a teoria tem por lócus de atuação a prática, possibilitando transformações e se alimentando da mesma" (SANTOS, 2012, p. 28).

Na perspectiva marxista, a teoria é um modo de ler a realidade e interpretá-la a fim de apreender suas determinações e contradições, seu movimento e sua direção, se coloca, portanto, como fundamento da ação, contribuindo para que se identifique os obstáculos que se colocam à prática. É, pois, uma forma de antecipação ideal de resultados para a ação. A prática, por conseguinte, é "uma ação direcionada a um objeto com a finalidade de transformá-lo em algo inicialmente previsto [...], ou seja, já se tem um resultado ideal ou finalidade, porém, o resultado final é um produto efetivo, real [...]. Assim, a prática implica, necessariamente, objetivação" (SANTOS, 2012, p. 31). É a partir desta concepção de teoria e prática que é possível a profissão romper com o pragmatismo e com o discurso de que "na prática a teoria é outra", posto que, conforme (SANTOS, 2012, p. 27-28):

\begin{abstract}
na perspectiva do materialismo dialético, na prática a teoria só pode ser a mesma, uma vez que ela é o lugar onde o pensamento se põe. A teoria quer, justamente, conhecer a realidade, extrair as legalidades, as racionalidades, as conexões internas postas nos produtos da ação prática dos homens, assim não há como na prática a teoria ser outra. Essa posição só é verdadeira se se considerar por teoria algo pronto, acabado, que se ajusta a uma prática. Aqui teoria é constante movimento, movimento que acompanha a prática e pode contribuir com ela.
\end{abstract}

Uma vez entendendo que a prática se coloca como objeto do conhecimento e é nela que está o critério de verdade - tal critério, porém, não se coloca de forma imediata como querem os pragmáticos ao defenderem a utilidade do conhecimento -, esta se coloca como prática transformadora somente a partir da reflexão teórica, que consiste na reprodução a nível do intelecto das determinações da prática. Neste sentido, a teoria só existe em relação à prática e esta por sua vez é o fundamento da teoria. É somente a partir desta concepção de teoria e de prática que a profissão de Serviço Social poderá intervir na realidade a partir de um fundamento teórico que aponte para escolhas metodológicas éticas, direcionadas por uma postura política crítica e consciente, articuladas a partir de seu arsenal técnico-operativo.

\title{
3 Relação teoria e prática no estágio supervisionado em Serviço Social
}

Compreendendo que a profissão ganha conformidade através das dimensões teórico-metodológica, ético-política e técnico-operativa, no espaço do cotidiano, e que este é o lugar por excelência da reprodução dos indivíduos sociais, é neste espaço que devemos pensar as contradições do exercício e da formação profissional e tentar superá-las. Conforme aponta Guerra (2012, p. 46):

o cotidiano profissional é pleno de requisições de cumprimento de normas, regulamentos, orientações ou decisões de superiores, os quais impõem ao profissional a necessidade de respostas às mesmas. Neste contexto, a prioridade é responder aos fenômenos, não importa como, disto resultando um conjunto de respostas profissionais rápidas, ligeiras, irrefletidas, instrumentais, baseadas em analogias, experiências, senso comum, desespecializadas, formais, modelares, em obediência a leis e superiores, sem a qualificação necessária para distingui-las de respostas atribuídas por leigos.

É necessário romper com as requisições profissionais hierarquizadas e burocráticas e se colocar como profissionais críticos e propositivos, a partir de um posicionamento qualificado diante da realidade, tal postura passa por análise e investigação da realidade a fim de propor ações que venham transformá-la. Setúbal (2007, p. 67), afirma a esse respeito que:

Consideram-se inconteste as necessidades do Serviço Social (na busca de aproximação do seu objeto histórico) de procurar entender, explicar, conhecer e apreender a realidade naquilo que lhe é essencial, com 
o apoio de procedimentos metodológicos cuidadosamente planejados e de uma sólida fundamentação teórica; realizar análise de situações concretas iniciando com a pesquisa da prática profissional na sua contextualidade e temporalidade histórica, ou seja, apreender a prática profissional no interior das múltiplas determinações do capitalismo contemporâneo.

Embora nenhuma ação esteja isenta de sentido, significação, prévia ideação, o fato de, às vezes, não refletirmos sobre o que vamos executar nos leva a pôr em prática projetos que têm ido de encontro aos princípios profissionais e, ao invés de garantir a transformação social, têm nos colocado como reprodutores das relações sociais capitalistas. Urge o fortalecimento de um perfil profissional crítico, reflexivo e propositivo, no intuito de implementar ações e conduzir os serviços sociais na perspectiva da emancipação humana. Justifica-se, pois, a necessidade e a utilidade da pesquisa no exercício profissional do assistente social, visto a urgência de superar a separação entre teoria e prática e a crença de que a teoria e a investigação cabem apenas aos intelectuais/ profissionais que estão no contexto acadêmico. A supervisão de estágio é o espaço privilegiado de articulação entre investigação e intervenção e que tal compreensão de realidade deve ser estimulada tanto por supervisores de campo, quanto acadêmicos. A partir da experiência que tivemos enquanto supervisora acadêmica, listaremos aqui algumas possibilidades para pensar a articulação teoria e prática na supervisão de estágio, que, sem dúvida, fortalecerá não só a formação profissional do estágio, mas contribuirá para a formação continuada do supervisor de campo e para o compartilhamento de experiências entre este e o supervisor acadêmico.

A primeira questão a considerar é que a supervisão de

...a teoria só existe em relação

à prática e esta por sua vez é o fundamento da teoria. É somente a partir desta concepção de teoria e de prática que a profissão de Serviço Social poderá intervir na realidade a partir de um

\section{fundamento teórico que aponte}

para escolhas metodológicas

éticas, direcionadas por uma

postura política crítica e

consciente, articuladas a partir

de seu arsenal técnico-

operativo. estágio precisa ser entendida como uma atribuição profissional e, portanto, uma vez aceito o estagiário o profissional supervisor deve estar preparado para este processo de supervisão. O fato é que muito pouco se tem discutido sobre formação profissional e supervisão de estágio nas disciplinas de estágio em Serviço Social e, visto que a perspectiva pragmática de entendimento do estágio ainda está bastante presente no imaginário de supervisores e estudantes, tem sido reproduzida uma supervisão de estágio que se limita ao repasse dos casos atendidos, à descrição da realidade de forma superficial e, quando muito, ao acesso do estagiário aos instrumentos técnico-operativos do exercício profissional.

Boa parte dos assistentes sociais, diante do cenário de precarização das condições éticas e técnicas de trabalho, têm se recusado a receber estagiários, e quando os recebem, demonstram que ter um estagiário é ter trabalho a mais, pois vai ser necessário estudar para orientá-lo. Não se pode negar que ter um estagiário tem se colocado para muitos profissionais como a única possibilidade que é posta a ele de articular aspectos teóricos com o movimento do real, ou seja, de tirá-lo da zona de conforto, própria do cotidiano: a confiança. Porém, cabe aqui uma reflexão: não deveria o profissional se preocupar em estudar, em "se atualizar" somente quando estiver na responsabilidade de supervisionar, uma vez que a qualidade dos serviços prestados à população depende de sua competência teórico-metodológica, ético-política e técnico-operativa. A qualificação profissional não deve ser colocada como responsabilidade individual do profissional. Neste sentido, a formação continuada para supervisores de estágio é imprescindível, principalmente quando é possível oportunizar espaços de debate entre supervisão acadêmica e supervisão de campo. Como supervisora acadêmica, tivemos algumas experiências interessantes junto aos supervisores de campo através do Curso de Capacitação para Supervisores de Estágio promovido pela nossa Instituição como curso de extensão com carga horária de 120 horas, com o tema Supervisão de Estágio em Serviço Social: dimensões éticopolítica e técnico-operativa, onde foi possível discutir os fundamentos éticos do exercício profissional, os principais desafios à profissão em um cenário de focalização das políticas sociais, e de retrocesso do ponto de vista da garantia dos direitos, e em que medida isto repercute no cotidiano profissional e nas requisições profissionais. A partir deste curso, que teve duração de oito meses, foi possível uma maior aproximação 
entre os profissionais da região, oportunizando construir pautas coletivas para debate juntamente com as entidades representativas da profissão e se fortalecer politicamente diante das requisições postas de maneira equivocada em seus espaços de trabalho.

Neste curso, discutimos sobre o papel da supervisão de estágio e refletimos sobre algumas estratégias que poderiam ser adotadas pelos assistentes sociais a fim de fortalecer o exercício profissional, através da superação das práticas superficiais, e com isso qualificar o processo de supervisão, são eles: necessidade de sair do imediatismo, criando espaços de resistência e lutas coletivas através de reuniões da categoria para discutir as demandas do cotidiano e traçar estratégias conjuntas; buscar o apoio junto aos movimentos sociais e outras profissões que compartilhem dos mesmos princípios éticos a fim de fortalecer a defesa intransigente dos direitos humanos e se contrapor à burocracia institucional; ocupar de forma qualificada os espaços de participação e de deliberação das políticas sociais como os Conselhos e as Conferências; realizar trabalho socioeducativo de base com a população, criando espaços de participação comunitária, chamando a população para ocupar os espaços institucionais.

Referente às ações profissionais nos espaços sócio-ocupacionais, é necessário: reuniões de equipe e com instituições parceiras para traçar estratégias coletivas e realizar o planejamento de ações a partir de estudos e pesquisas sobre as condições de vida da população e de como as políticas sociais chegam até ela; criação de instrumentais, fluxos, pactuação de responsabilidades no trabalho interdisciplinar e no trabalho intersetorial; e, além dessas ações das quais devem participar os estagiários, algumas outras são essenciais ao estágio e ao processo de formação profissional: compartilhar experiências, saberes e informações com os supervisores acadêmicos e com os estagiários, uma estratégia que tem tido resultados interessantes têm sido os fóruns locais de estágio, as reuniões da comissão de estágio e os seminários de processos de trabalho realizados dentro das disciplinas de estágio, onde supervisores e estagiários discutem e refletem sobre a instrumentalidade da profissão e os limites do cotidiano; além disso, realizar grupos de estudos com os estagiários e supervisores acadêmicos e de campo, e atividades de planejamento da supervisão de estágio tem mostrado que se coloca como importante estratégia de articulação entre teoria e prática na formação profissional.

\section{Considerações finais}

A formação profissional em Serviço Social tal como entendida na contemporaneidade é fruto de um movimento histórico da profissão que foi se renovando, criticando e rompendo com posturas teóricometodológicas conservadoras, construindo um novo perfil profissional e uma direção que buscam se contrapor ao projeto burguês-neoliberal, tendo como imagem social e autoimagem uma profissão que busca defender de forma intransigente os direitos de seus usuários, remando contra a corrente, em tempos de negação destes. Neste sentido, é impossível pensar uma prática propositiva, criativa, articulada e crítica sem uma fundamentação teórica que possibilite romper com o imediatismo, a superficialidade e a espontaneidade, próprios do cotidiano. É urgente para o Serviço Social o questionamento sobre os rumos que a formação e o exercício profissional têm tomado nos últimos anos a partir da interferência de correntes do pensamento pós-moderno na profissão, seja fundamentando o retorno de práticas empiristas, desistoricizadas, fragmentadas e imediatistas, com claro retorno do conservadorismo, psicologismo e instrumentalismo, seja a partir da produção de análises superficiais e mistificadoras da realidade, que tem levado muitos profissionais a procurarem individualmente a melhor forma de atuar e dar respostas à realidade, fragilizando o projeto profissional.

O debate acerca da relação teoria e prática na perspectiva marxiana se torna urgente e necessário se quisermos garantir a hegemonia da direção do projeto ético-político da profissão e um processo de estágio que possibilite ao assistente social em formação, partir do real, analisá-lo, construir as possibilidades de intervenção e buscar sua transformação.

\section{Referências}

ASSOCIAÇÃO BRASILEIRA DE ENSINO E PESQUISA EM SERVIÇO SOCIAL (ABEPSS). Política Nacional de Estágio PNE, 2010.

CONSELHO FEDERAL DE SERVIÇO SOCIAL (CFESS). Resolução n. 533, de 29 de setembro de 2008, que regulamenta a supervisão direta de estágio. Disponível em: www.cfess.org.br. Acesso em: 25 fev. 2015.

CONSELHO FEDERAL DE SERVIÇO SOCIAL (CFESS). Lei n. 8662, de 07 de junho de 1993, que dispõe a profissão de Assistente Social. Disponível em: www.cfess.org.br. Acesso em: 25 fev. 2015. 
FORTI, V.; GUERRA, Y. Na prática a teoria é outra? In: Serviço Social: Temas, Textos e Contextos. Rio de Janeiro: Lumen

Juris, 2013. p. 3-22.

GUERRA, Y. D. A instrumentalidade do Serviço Social. São Paulo: Cortez, 2011.

. Instrumentalidade do processo de trabalho e Serviço Social. In: Revista Serviço Social e Sociedade. n. 62, ano XX, mar. São Paulo: Cortez, 2000.

Expressões do pragmatismo no Serviço Social: reflexões preliminares. In: Revista Katálysis. vol.16, 2013, p. 39-49. Disponível em: http://www.scielo.br/scielo.php?script=sci_arttext\&pid=S1414-49802013000300004. Acesso em: 22 fev. 2015.

GUERRA, Y. A dimensão técnico-operativa do Serviço Social. In: GUERRA, Y.; BACKX, S.; SANTOS, C. M. dos. A dimensão técnico-operativa no Serviço Social: desafios contemporâneos. Minas Gerais: UFJF, 2012.

GUERRA, Y. D.; BRAGA, M. E. Supervisão em Serviço Social. In: Serviço Social: direitos sociais e competências profissionais. Brasília: CFESS/1, 2009.

HAACK, S. Pragmatismo. In: NICHOLAS, B.; TSUI-JAMES, E. P. Compêndio de Filosofia. Edições Loyola, 2002 p. 641-657. LEWGOY, A. M. B. Supervisão de estágio em Serviço Social: desafios para a formação e o exercício profissional. São Paulo: Cortez, 2010.

NETTO, J. P. Ditadura e Serviço Social: uma análise do serviço social no Brasil pós-64. São Paulo: Cortez, 2010.

Razão, Ontologia e Práxis. In: Revista Serviço Social e Sociedade, n. 44, ano XV, abr. São Paulo: Cortez, 1994.

ORTIZ, F. G. O Serviço Social no Brasil: os fundamentos de sua imagem e da auto-imagem de seus agentes. Rio de Janeiro: E-papers, 2010. Notas sobre as Diretrizes Curriculares: avanços, impasses e desafios. In: GUERRA, Y.; LEITE, J.; ORTIZ, F. G. Temas Contemporâneos: o Serviço Social em Foco. São Paulo: Expressão Popular, 2013.

RIBEIRO, E. B. O Estágio no Processo de Formação dos Assistentes Sociais. In: FORTI, V.; GUERRA, Y. Serviço Social: Temas, Textos e Contextos. Rio de Janeiro: Lumen Juris, 2013.

SANTOS, L. L. Serviço Social na América Latina: 1970-1980. Entrevista Memória com Leila Lima Santos. In: Revista Em Pauta, n. 20, 2007. p. 163-179.

SANTOS, C. M. dos. Na prática a teoria é outra? Mitos e dilemas na relação entre teoria, prática, instrumentos e técnicas no Serviço Social. Rio de Janeiro: Lumen Juris, 2012.

SETÚBAL, A. A. Desafios à pesquisa no Serviço Social: da formação acadêmica à prática profissional. In: Revista Katálysis. 2007, vol.10, p. 64-72.

YAZBEK, C. Fundamentos Históricos e Teórico-Metodológicos do Serviço Social. In: Serviço Social: direitos sociais e competências profissionais. Brasília: CFESS/ABEPSS, 2009.

\section{Notas}

1 De acordo com Guerra (2000, p. 16): “a razão instrumental é uma racionalidade subordinada e funcional: subordinada ao alcance dos fins particulares, dos resultados imediatos, e funcional às estruturas. Constitui-se num conjunto de atividades, num conjunto de funções, não se importando nem com a correção dos meios nem com a legitimidade dos fins. Por isso funcional ao capital. Subsume os atributos das coisas aos seus aspectos quantitativos. Limita-se a garantir eficácia e eficiência".

2 A pesquisaé fruto de revisão de literatura e de uma síntese de análises realizadas enquanto supervisora acadêmica do Curso de Serviço Social do Instituto Federal de Educação, Ciência e Tecnologia do Ceará (IFCE), Campus Iguatu, a partir dos momentos de supervisão com os estudantes e dos encontros com os supervisores de campo, seja no próprio campo de estágio ou em espaços construídos para debater o exercício profissional e o estágio supervisionado em Serviço Social.

3 "Entendemos por renovação o conjunto de características novas que, no marco das constrições da autocracia burguesa, o Serviço Social articulou, à base do rearranjo de suas tradições e da assunção do contributo de tendência do pensamento social contemporâneo, procurando investir-se como instituição de natureza profissional dotada de legitimidade prática, através de respostas a demandas sociais e da sua sistematização, e de validação teórica, mediante a remissão às teorias e disciplinas sociais" (NETTO, 2010, p. 131).

4 De acordo com Netto (2010, p 154), a perspectiva modernizadora consistia em "um esforço no sentido de adequar o Serviço Social, enquanto instrumento de intervenção inserido no arsenal de técnicas sociais a ser operacionalizado no marco de estratégias de desenvolvimento capitalista, às exigências postas pelos processos sociopolíticos emergente no pós-64 [...] seus grandes monumentos, sem dúvidas, são os textos dos seminários de Araxáe Teresópolis".

5 De acordo com (NETTO, 1994, p. 29), a razão formal-abstrata analisa a realidade decompondo-a, classificando-a, distinguindo-a, "com ênfase nas inferências por via dedutiva e mediante modelos de caráter lógico e matemático. Oentendimento é posto como um modo operativo da razão, que não critica os conteúdos dos materiais sobre que incide" Esta modalidade operativo-racional "é essencialmente limitada na escala em que -não envolvendo o caráter negativo e, portanto crítico da razão, específico da sua dimensão dialética-esgota e reduz a racionalidade aos comportamentos manipuladores do sujeito em face do mundo objetivo".

6 Para o aprofundamento desta questão, conferir Netto (2010, p. 177-193) e Guerra (2000, p. 26-27).

7 O movimento da Escola Nova foi influenciado pelas ideias de Jonh Dewey, um dos fundadores do pragmatismo norte-americano, que defendia o ensino-aprendizagem como processo que deveria ser focado no aluno, e não mais no professor. 


\section{Moíza Siberia Silva de Medeiros}

moizasiberia@gmail.com

Doutoranda em Serviço Social pela Universidade Federal do Rio de Janeiro (UFRJ)

Professora de Serviço Social do Instituto Federal de Educação, Ciência e Tecnologia do Ceará (IFCE).

\section{IFCE}

Rodovia Iguatu/Várzea Alegre, Km 05, Vila Cajazeiras

Iguatu - Ceará - Brasil

CEP: $63.503-790$ 